\title{
Misdiagnosis of a twin pregnancy with double-corner uterine rupture following salpingectomy and protrusion of the amniotic sac as an adnexal cyst: a case report
}

\author{
Jinhua Dong* (D), Yunfei Cao, Qiang Ma, Lili Xue and Weiying Zhu
}

\begin{abstract}
Background: Salpingectomy-associated uterine rupture during intrauterine pregnancy is rare in the clinic. We report a case of pregnancy with bilateral rupture of the uterine horns after bilateral salpingectomy.

Case presentation: A 30-year-old woman of Han ethnicity presented with right epigastric pain at 28 weeks and 6 days of gestation. Examination by colour Doppler ultrasound showed the following: "Twin live births with normal foetal umbilical artery blood flow indexes and a $183 \mathrm{~mm} \times 112 \mathrm{~mm}$ anechoic zone in the right front of the uterus". Initially, we made an incorrect judgement wherein we considered the amniotic sac that was protruding into the abdominal cavity to be an adnexal cyst. Fortunately, the diagnosis of uterine rupture was confirmed before the protruded amniotic sac broke. The mother did not bleed much, and the twin foetuses survived in our case.

Conclusion: A previous history of salpingectomy via laparoscopy could be a risk factor for uterine rupture in pregnant women. Attention should be paid to rare complications of pregnancy. To avoid adverse events, we should pay special attention to women with a history of laparoscopic salpingectomy who complain about abdominal discomfort and offer them a relevant ultrasound examination.
\end{abstract}

Keywords: Uterine rupture, Salpingectomy, Intrauterine pregnancy

\section{Background}

Usually, patients with a previous history of uterine surgery (including caesarean section or hysteromyomectomy) have a greater risk of rupture, while those without scars have a very low risk of rupture $[1,2]$. The typical uterine rupture is often accompanied by severe abdominal pain, vaginal bleeding, loss of the foetal heartbeat, and uterine diminution. Generally, when the aforementioned symptoms occur, the foetus dies, and the mother's life is threatened [3]. Uterine rupture during intrauterine pregnancy due to salpingectomy is a rare and unusual type of rupture, and in most cases, the foetus dies before detection. In the case

\footnotetext{
* Correspondence: 16084023@qq.com

Department of Obstetrics and Gynecology, The Women and Children Hospital Affiliated to Jiaxing University, 2468 Middle Ring Eastern Road, Jiaxing City 314000, Zhejiang, China
}

described here, we were lucky to have the opportunity to confirm the diagnosis and avoid the disastrous consequences of the condition.

\section{Case presentation}

A 30-year-old woman of Han ethnicity, at 28 weeks and 6 days of gestation, complained of right epigastric pain 3 $\mathrm{h}$ before being seen and was immediately admitted to the hospital on May 13, 2016. She had not given birth but had a history of two right fallopian tube pregnancies. Fearing that she would have the same experience again, she gave up trying for a natural pregnancy and underwent laparoscopic bilateral salpingectomy using bipolar electrosurgical coagulation in a local hospital. The operation was a simple salpingectomy, without the involvement of the uterine horn. Therefore, she received a recommendation for 
in vitro fertilization and embryo transfer after four months. Two frozen embryos were transplanted, and colour Doppler ultrasonography showed "double chorionic double amniotic sac twins" at 6 weeks of gestation. Until May 14, there had been no special abnormalities during her prenatal examinations. On the day of admission, there was no obvious cause of her right upper abdominal minimal and obscure pain. The pain lasted for $20 \mathrm{~min}$, after which she experienced relief without lower abdominal pain. The patient had no nausea or vomiting, no diarrhoea, and no symptoms of vaginal bleeding or fluid leakage. The foetal movement was normal. Physical examination revealed the following: P, 123 beats/ min; R, 19 beats/min; BP, 113/68 mmHg; and T: $36.4{ }^{\circ} \mathrm{C}$. No significant abnormalities in cardiac and pulmonary auscultation were found. No tenderness or rebound pain was observed in the abdomen. Colour Doppler ultrasound showed "Twin live births with normal foetal umbilical artery blood flow indexes and a $183 \mathrm{~mm} \times 112 \mathrm{~mm}$ anechoic zone in the right front of the uterus". We considered the cystic mass on the right anterior side of the uterus to be an adnexal cyst. Routine blood tests on the day after admission showed the following: WBC, 18.7*10^9/L; NE\%, 84.8; and HGB, $104 \mathrm{~g} / \mathrm{l}$. On May 15, the patient felt fewer foetal movements than before without any other discomfort. We re-examined the baby by colour Doppler ultrasound. Two live foetuses were found in the uterus. The muscular layer of the right uterine wall was ruptured with a width of approximately $21 \mathrm{~mm}$. On the right side of the uterus, there was a $139 \mathrm{~mm} \times 118$ $\mathrm{mm}$ anechoic area, which was connected to the uterus. In the anechoic area, foetal limbs and strip-shaped strong echoes were observed (Fig. 1). There was no amniotic fluid around the twins. At that time, no obvious effusion was found in the abdominal cavity of the pregnant woman. Emergency caesarean section was performed under combined spinal-epidural anaesthesia. Two male infants

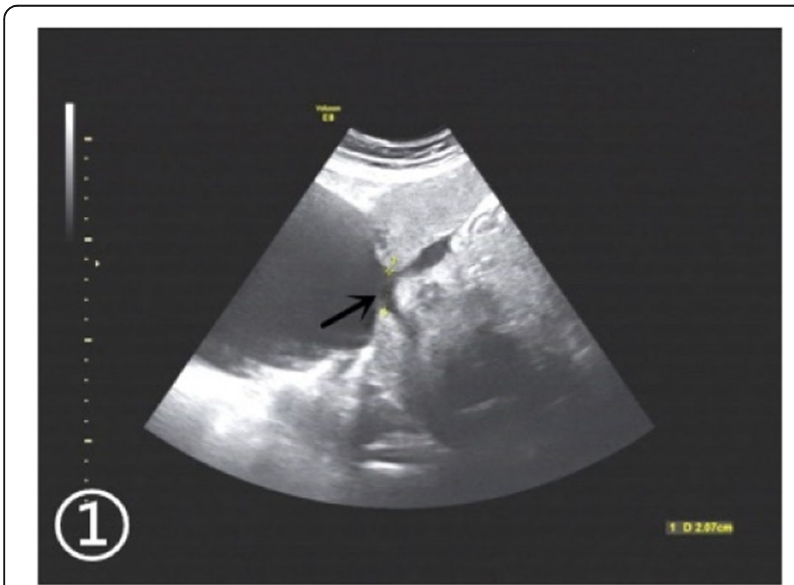

Fig. 1 Ultrasound scan image: myometrial defect at the right uterine horn and hypoechoic liquid dark area connected to the uterine cavity weighing 1260/1240 g were delivered through a lower uterine incision. The Apgar scores at $1 \mathrm{~min}$ and $5 \mathrm{~min}$ were $6 / 7$ and $6 / 6$, respectively. Intraoperative examination showed that the amniotic sac, with a volume of approximately $13 \mathrm{~cm} \times 10 \mathrm{~cm} \times 10 \mathrm{~cm}$, was bulging from the right corner of the uterus to the abdominal cavity, with clear amniotic fluid (Fig. 2). At the same time, we found a $0.5 \mathrm{~cm} \times 0.5 \mathrm{~cm}$ rupture in the left corner of the uterus with a small amount of active haemorrhage (Fig. 3). We repaired and sutured the uterine rupture on both sides and increased the anti-inflammatory treatment after the operation. The patient recovered well and was discharged from the hospital on the 7th day after surgery.

\section{Discussion and conclusion}

Uterine rupture during intrauterine pregnancy after salpingectomy is a rare clinical adverse event [4]. To our knowledge, no more than 10 cases have been reported in the literature, most of which are unilateral ruptures of a uterine horn [5]. Only one case of spontaneous rupture of both corners of the uterus after bilateral salpingectomy via laparoscopy was reported, by Inovay and colleagues [6]. The rupture occurred 14 weeks after in vitro fertilization, with vaginal spotting and intense abdominal pain; unfortunately, when a defect in the uterine wall was suspected, the foetus had died. In our case, there was bilateral rupture of the uterine horns, the amniotic sac did not break when it protruded from the ruptured uterus, and the twin foetuses survived. This type of case is extremely rare in clinical practice.

Uterine rupture in patients without apparent risk factors is associated with non-specific signs and symptoms that can postpone the diagnosis. Atypical uterine rupture cannot be detected in time, and the delay is often the

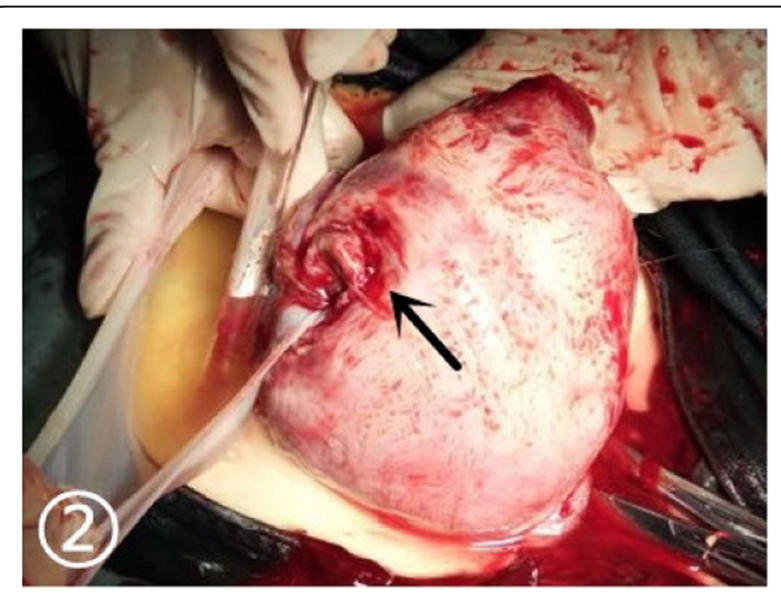

Fig. 2 Intraoperative findings: Ruptured right uterine horn; amniotic membrane and amniotic fluid 


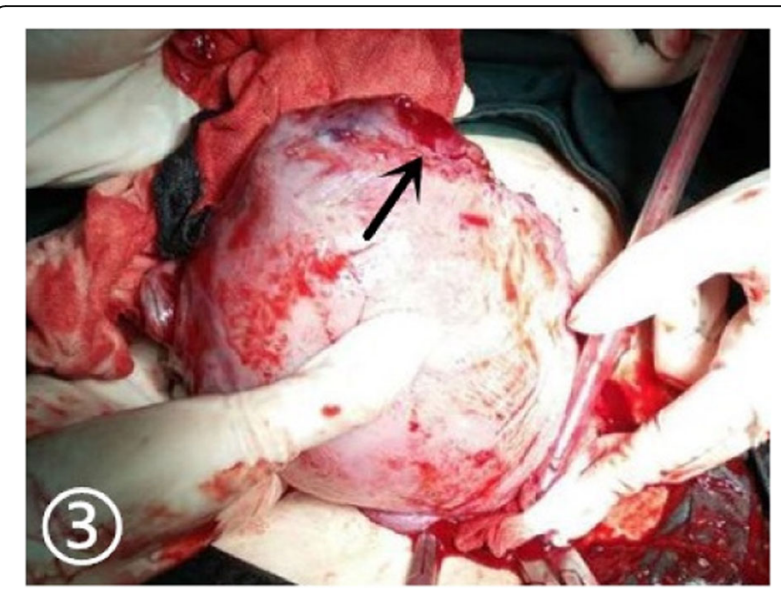

Fig. $3 \mathrm{~A} 0.5 \mathrm{~cm} \times 0.5 \mathrm{~cm}$ rupture in the left corner of the uterus with a small amount of active haemorrhage. The black arrow indicates the rupture site

main cause of the adverse outcomes of mothers and infants [7]. In our case, as the procedure was only a simple bilateral salpingectomy and did not involve the corners of the uterus, we neglected the possibility of uterine rupture. The symptom of abdominal pain was obscure and disappeared quickly, which confounded the diagnosis. While evaluating previous cases of uterine rupture following salpingectomy, we found that a few of them had no obvious symptoms and that their ruptures were only unintentionally found during caesarean section [5]. Sometimes, the abdominal pain is similar to that of a threatened preterm delivery, so the possibility of uterine rupture is easy to ignore. When the condition progresses, it is often too late to alleviate the shock symptoms. In our case, rupture of the uterus was found on the second ultrasound examination; however, the patient had no discomfort but did show decreased foetal movement. Surprisingly, the amniotic sac protruded from the rupture of the uterus for 2 days without rupturing, until there was no amniotic fluid around the foetus, resulting in fewer foetal movements. Although this complication is rare, it can be detected and diagnosed by ultrasound in early pregnancy, even in asymptomatic patients, as long as there is sufficient diagnostic awareness.

Why does uterine rupture occur after salpingectomy? In addition to the surgical method, the time interval between salpingectomy and conception is very important. It is generally believed that laparoscopic salpingectomy can cause thermal damage, which results in defects in the corners of the uterus [8]. The recommended pregnancy interval is usually 2 years after uterine injury [9]. The interval has been reported to be less than 12 months for $67 \%$ of cases of uterine rupture in a non-ectopic pregnancy group (after salpingectomy) [5]. The cause of uterine rupture in this case was considered to be pregnancy at only 4 months after laparoscopic bilateral salpingectomy. Perhaps, poor healing after salpingectomy and rapid uterine enlargement in the twin pregnancy resulted in rupture of the injury sites.

By studying this case, we have gained some experience and learned several lessons. The uterine rupture had occurred by the time of the first ultrasound examination but was not clearly diagnosed by ultrasound. If the patient's condition progressed rapidly, the consequences would be worrying. Therefore, when performing ultrasound scans, the cystic mass, especially its relationship to the uterus and its blood flow, should be carefully evaluated. If necessary, an experienced ultrasound doctor should be consulted. In addition, rupture of the left uterine horn was not diagnosed by the preoperative ultrasound in this case. The rupture of the right uterine horn was confirmed, and the ultrasound doctor was eager to complete the ultrasound examination without careful resolution. In addition, this may be because the rupture port was too small to be examined by ultrasound.

A previous history of salpingectomy via laparoscopy could be a risk factor for uterine rupture in pregnant women. To avoid adverse events, we should pay special attention to women with a history of laparoscopic salpingectomy who complain of abdominal discomfort and offer them a relevant ultrasound examination.

\section{Abbreviations}

HGB: Haemoglobin; NE\%: Percentage of neutrophils; WBC: White blood cell

\section{Acknowledgements}

We would like to acknowledge Dr. Xiaolin Hua and all of our team members who were involved in the case management.

Authors' contributions

DJH participated in the design, writing and organization of the manuscript CYF and MQ conceived of the study and designed it. XLL and ZWY participated in the collection and analysis of the data for the case. All authors read and approved the final manuscript.

\section{Funding}

This work was supported by funds from Jiaxing Science and Technology Planning Project (Grant No. 2016AY23060).

Availability of data and materials

The datasets created and/or analysed during the current study are available from the corresponding author on reasonable request.

Ethics approval and consent to participate

The research was approved by the Ethics Committee of The Women and Children Hospital Affiliated with Jiaxing University. Consent to participate is not applicable due to the nature of this study.

Consent for publication

Written, informed consent was obtained from the patient for publication of this case report and accompanying images.

Competing interests

The authors declare that they have no competing interests. 
Received: 19 August 2019 Accepted: 28 January 2020

Published online: 03 February 2020

\section{References}

1. Thisted DLA, Mortensen LH, Krebs L. Uterine rupture without previous caesarean delivery: a population-based cohort study. Eur J Obstet Gynecol Reprod Biol. 2015;195:151-5.

2. Ofir K, Sheiner E, Levy A, Katz M, Mazor M. Uterine rupture: risk factors and pregnancy outcome. Am J Obstet Gynecol. 2003;189:1042-6.

3. Astatikie G, Limenih MA, Kebede M. Maternal and fetal outcomes of uterine rupture and factors associated with maternal death secondary to uterine rupture. BMC Pregnancy Childbirth. 2017;17(1):117.

4. Huang YT, Yim SL, Kapurubandara S, et al. Antepartum uterine rupture at 29 weeks gestation following unilateral salpingectomy and review of literature. BMJ Case Rep. 2017:2017. https://doi.org/10.1136/bcr-2015-211359.

5. Stanirowski PJ, Trojanowski S, Slomka A, et al. Spontaneous rupture of the pregnant uterus following salpingectomy: a literature review. Gynecol Obstet Investig. 2018;80(2):73-77.

6. Inovay J, Marton T, Urbancsek J, et al. Spontaneous bilateral cornual uterine dehiscence early in the second trimester after bilateral laparoscopic salpingectomy and in-vitro fertilization: case report. Hum Reprod. 1999; 14(10):2471-3.

7. Abbas AM, Shehata MA, Fathalla MM. Maternal and perinatal outcomes of uterine rupture in a tertiary care hospital: a cross-sectional study. J Matern Fetal Neonatal Med. 2018:1-121. https://doi.org/10.1080/14767058.2018. 1463369

8. Xiaoyi W, Wei J, Huan X, et al. Characteristics of uterine rupture after laparoscopic surgery of the uterus: clinical analysis of 10 cases and literature review. J Int Med Res. 2018;46(9):3630-9.

9. Reif $P$, Brezinka $C$, Fischer $T$, et al. Labour and childbirth after previous caesarean section. Geburtshilfe Frauenheilkd. 2016:76(12):1279-86.

\section{Publisher's Note}

Springer Nature remains neutral with regard to jurisdictional claims in published maps and institutional affiliations.

Ready to submit your research? Choose BMC and benefit from:

- fast, convenient online submission

- thorough peer review by experienced researchers in your field

- rapid publication on acceptance

- support for research data, including large and complex data types

- gold Open Access which fosters wider collaboration and increased citations

- maximum visibility for your research: over $100 \mathrm{M}$ website views per year

At BMC, research is always in progress.

Learn more biomedcentral.com/submissions 